\title{
An Error Analysis of English Paragraphs Written by First Year Debre Markos College Teacher Education Students: A Discourse Analysis Perspective
}

\author{
Kebede Gedefaw Abie \\ MA in English literature, Lecturer in the Department of English Language and Literature at Debre Markos \\ University, Ethiopia \\ Mr. Mersha Kenefergib Asefa \\ MA in TEFL, Lecturer in the department of English Language and Literature at Debre Markos University, \\ Ethiopia
}

\begin{abstract}
The objective of this study was to identify the types of errors in paragraph writing in English made by first year Debre Markos College Teacher Education (DMCTE) students. Eight hundred and forty students was the total population. From the total population, 260 students were selected to write a paragraph about their autobiography for analysis using stratified sampling technique. Ferris's (2005) category of errors was used as a framework for analysis. The common errors found were morphological, syntactic, lexical and mechanical errors which contain many sub-branches in each. The numbers of errors were calculated as percentage. Based on the formats used in the study, 1730 errors were made by the students. From these, 604 (34.9\%) morphological, 96 (5.54\%) mechanical, $542(31.3 \%)$ syntactic, and 488(28.2\%) lexical errors were identified. The highest error students commit from the above lists was morphological error like verb error, noun error, and article or determiner errors. This shows that most errors committed by DMCTE students are laid on morphological errors and the least errors are on mechanical errors. This indicates that most of the students couldn't identify the major components of morphological structures of sentence in English language. Finally, teachers should be more aware of the most common types of errors that students regularly commit and provide the necessary follow up work to check the problem areas which is useful to give feedback to improve students writing skills. .
\end{abstract}

Keywords: Error Analysis, paragraph writing, students

DOI: $10.7176 /$ JLLL/62-02

Publication date: November $30^{\text {th }} 2019$

\subsection{Introduction}

Discourse analysis, which refers to a broad area of inquiry that involves several dimensions and spans in a variety of disciplines. As Chomsky (1965) stated, there is no limit to the number of possible sentences that can be generated from the grammar and lexicon of a language. Discourse analysis may, broadly speaking, be defined as the study of language viewed communicatively and/or of communication viewed linguistically. Any more detailed spelling out of such a definition typically involves reference to concepts of language in use, language above or beyond the sentence, language as meaning in interaction, and language in situational and cultural context.

Discourse analysis is a primarily linguistic study examining the use of language by its native population whose major concern is investigating language functions along with its forms, produced both orally and in writing. Moreover, identification of linguistic qualities of various genres, vital for their recognition and interpretation, together with cultural and social aspects which support its comprehension, is the domain of discourse analysis. To put it in another way, the branch of applied linguistics dealing with the examination of discourse attempts to find patterns in communicative products as well as and their correlation with the circumstances in which they occur, which are not explainable at the grammatical level (Carter 1993:23).

A significant contribution to the evolution of discourse analysis has been made by British and American scholars. In Britain the examination of discourse turned towards the study of the social functions of language. Research conveyed at the University of Birmingham fruited in creating a thorough account of communication in various situations such as debates, interviews, doctor-patient relations, paying close attention to the intonation of people participating in talks as well as manners particular to circumstances. Analysis of the factors essential for succession of decently made communication products on the grounds of structural-linguistic criteria was another concern of British scholars. Americans, on the other hand, focused on examining small communities of people and their discourse in genuine circumstances. Apart from that, they concentrated on conversation analysis inspecting narratives in addition to talks and the behavior of speakers as well as patterns repeating in given situations. Division and specification of types of discourse along with social limitations of politeness and thorough description of face saving acts in speech is also American scholars' contribution (McCarthy 1991:6). 
Moreover, it is a general term for many approaches to analyzing written and spoken language use. Brown and Yule [1996] state that "discourse analysis" has come to be used with a wide range of meanings which cover a wide range of activities. McCarthy, M. [1991] says that Discourse analysis is concerned with the study of the relationships between language and the context in which it is used. I take the view of Brown and Yule [1996] that the term Discourse analysis is the study of how language used in linguistic products with reference to the social and psychological factors influence communication.

Of the inclusiveness of discourse, all linguistic aspects and practice of using the language, analyzing the errors in writing with discourse perspective is very important. Since English language has become a necessity all over the world, it is used as an international language among all nations in the world; therefore, the means of communication through this language will be oral and written forms. As result, we should make our writing smart as much as possible in order to foster our communication. Although, no doubt, learning English requires mastering the four language skills; listening, speaking, reading and writing. Writing requires thinking and cognitive processes to be produced. It is considered the most complex skill because it goes through different stages i.e., prewriting, writing and editing, to reach its final product. Trembley (1993) viewed writing as a hard and risky skill.

Additionally, writing involves different aspects such as spelling, punctuation, organization. etc. Despite its complexity, writing is very important for communication. It creates a communication channel between the writer and the reader. It is needed to transfer messages, letters, and knowledge, to take exams and to maintain learning. However, proficiency in one's native language does not necessarily lead to proficiency in L2 writing (Archibald, 2004). Many native speakers find difficulties in mastering the writing skill (Celce-Murcia,2001). Nonetheless, writing is a crucial skill that is poorly acquired, researches into writing problems seem to be behind those examining other language areas (Klassen, 2001). Chidambaram (2005) argued that writing is a conscious, deliberate and planned activity. Writing has been regarded as an alternative medium of language, as it gives permanence to utterances. Writing enables the transmission of ideas over vast distances of time and space and is a pre-requisite of a complex civilization.

Bloomfield (1933, p.21) observed that "writing is not language but merely a way of recording language by means of visible marks". It needs a systematized form by making use of the components namely graphemes, vocabulary, syntax, etc So as to make a decoder understand it clearly. Language is a storehouse of knowledge with many dimensions of production and reception, so a standard system is needed to record a language in coded form. Writing is a formof encoded symbols in the form of print or impression (Khansir, 2010). Writing being one of the four skills of listening, speaking, reading, and writing has always formed part of the syllabus in the teaching of English language. However, it has been used for a variety of purposes, ranging from being merely a 'backup' for grammar teaching to a major syllabus strand in its own right, where mastering the ability to write effectively is seen as a key objective for learners (Harmer 2004).

From the written discourse, paragraph is one of the types of discourse. A paragraph is the fundamental unit in a composition. A paragraph is a sentence or group of sentences that develop one idea or one point. Thus, a paragraph is built around that central idea. Each paragraph should have a topic sentence. The topic sentence presents the main idea of the paragraph. It is also called the controlling idea because it limits the subject of the paragraph.

It suggests ways of developing the thought. In a unified paragraph all sentences relate to the topic sentence by explaining it with facts, examples, and supporting details. Paragraph writing is the first step towards any form of writing. A suitable teaching of paragraph writing will help the learners to write a good writing Essay and Thesis.

The main focus of this research is to express opinions at the paragraph level. Therefore, Paragraph writing or the organization of a paragraph is of primary importance. However, writing builds larger units from smaller ones; that is, writers use words to make sentences, sentences to make paragraphs, and paragraphs to make such compositions as letters, reports, and college themes. Hart \& Reinking 1990:11).

Rajatanun (1988:95) said that a paragraph is a unit of writing which expresses one central idea and consists of two kinds of sentences: a topic sentence and a number of supporting statements.

Error analysis is one of the major topics in the field of second language acquisition research. Learner's errors are seen as a natural and vital part of the learning process. They are also seen as inevitable, since learners are encouraged to explore the target language. English language has a different system of grammatical rules. The learner of English as a second or foreign language is unaware of the existence of the particular system or rule in the English language (Khansir, 2010). Corder (1967) proposed the hypothesis that errors are evidence of learner's strategies of acquiring the language rather than signs of inhibition or interference of persistent old habits. He claimed that a systematic study of errors is essential in order to discover the learner's built-in syllabus and learning strategies. He added that this information arrived at through error analysis, would be useful to text book writers, teachers and learners.

Apart from differences between written and spoken language described beforehand it is obviously possible 
to find various types and classes of discourse depending on their purpose. Written texts differ from one another not only in genre and function, but also in their structure and form, which is of primary importance to language teachers, as the knowledge of arrangement and variety of writing influences readers' understanding, memory of messages included in the discourse, as well as the speed of perception. Moreover, written texts analysis provides teachers with systematic knowledge of the ways of describing texts, thanks to which they can make their students aware of characteristic features of discourse to which the learners should pay particularly close attention, such as cohesion and coherence. In addition, understanding these concepts should also improve learners' writing skills as well.

\subsection{Statement of the Problem}

Writing plays an essential role in language learning. Writing is defined as an art of a writer. Hyland (2003) mentions the value of writing "the ability to communicate ideas and information affectively through the global digital network is crucially dependent on good writing skills." It implies the fact that the mental representation by means of lexical manipulation is given in the form of script or marks in the process of writing. Writing is more complex in that it tests a person's ability to use a language and the ability to express ideas. As a result, a person needs to write not only coherently but correctly, which requires more time and effort (Liu and Braine 2005:623-624).

Now days, there has been a growing awareness of the importance of writing skill in English language at elementary schools, high schools, colleges and universities in Ethiopian curriculum. The writing skill is part of the English syllabus in colleges. Writing an English paragraph is a main activity as a result of the writing lesson in high schools and college education.

One of the major concerns of written discourse analysts is the relation of neighboring sentences and, in particular, factors attesting to the fact that a given text is more than only the sum of its component. It is only with written language analysis that certain features of communicative products started to be satisfactorily described, despite the fact that they were present also in speech, like for instance the use of 'that' to refer to a previous phrase, or clause (McCarthy 1991:37). Written language is more integrated than the spoken one which is achieved by more frequent use of some cohesive devices which apart from linking clauses or sentences are also used to emphasize notions that are of particular importance to the author and enable the reader to process the chosen information at the same time omitting.

Hence, it is very important for students to be taught how to write a paragraph. But DMCTE students have made different errors consciously or unconsciously while writing paragraphs, so making errors have impact on their academic achievement and the work endeavor. As English majoring student, they are expected to develop effective and well organized paragraph, they lack the skills of writing. Therefore, investigating the students' error in paragraph writing with discourse analysis perspective is not questionable to identify the errors they made, and to fill gaps opened due to the absence of related works on the topic under study. Thus, the researchers tried to answer the following research questions.

\section{Research questions}

1. What are the common types of linguistic errors in English paragraphs written by DMCTE students?

2. What are the features of organization of English paragraphs written by DMCTE students?

3. What are some suggestions for the teaching and learning of English paragraph writing at DMCTE

For this reason, we choose to do research on the topic "An Error Analysis of English Paragraphs Written by Students at DebreMarkos College of Teacher Education: A Discourse Analysis Perspective". This thesis is carried out with the hope that the research results will provide certain linguistically useful practical knowledge for teachers in charge of the English writing skill at colleges and improving the students' skill in writing an English paragraph.

\section{Objectives:}

Identify the common problems faced by the DMCTE students in the process of English paragraph writing. Investigate the discourse features of English paragraphs written by DMCTE students. Provide suggestions for teaching and learning English paragraph writing to DMCTE student

\section{Related Works}

James (1998:162) concluded that coherence is related primarily to content, to the conceptual relatedness of propositions. Liu and Braine (2005:623) investigated the use of cohesive devices in 50 argumentative compositions written by Chinese undergraduate non-English majors. Results showed that students were able to use a variety of cohesive devices in their writing, among which lexical devices formed the largest percentage of the total number of cohesive devices, followed by references and conjunctives.

Connell (2000:95-103) analyzed the kinds of errors Japanese students made on tests which required full, 
written sentences to get the results for constructing a suitable syllabus. Each error was analyzed on how it affected the understanding of the sentence in which it was used. The results showed that the use of subject in a sentence, the parts of speech and general word order created more problems than other grammatical aspects. Olsen (1999:191-205) carried out research in English written by Norwegian EFL learners. Language problems on different linguistic levels were analyzed and the theory of compensatory strategies was used. The results showed that less proficient learners had a higher number of grammatical, orthographic and syntactic errors, which can be attributed to cross-linguistic influence.

\section{Methods and Procedures}

\subsection{Research Design}

The design of the study was descriptive based on the combination of qualitative and quantitative approaches. Since the nature of the topic was convenient to employ both qualitative and quantitative approaches. The qualitative design was utilized to analyze the written paragraphs by the students. Moreover, the quantitative method was employed to identify which the types of errors the students made in their written paragraph.

\subsection{Study Population}

The study focused on Debre Markos Teachers Education College, Amhara Regional State, Ethiopia. Thus, the study population was Debre Markos Teachers Education College students. The study included only regular first year students in 2015 at Debre Markos Teachers Education College.

\subsection{Sampling Technique}

The total population of the study was 840 first year students who were taking the course Basic English course. From these students, 260 students' were selected by using stratified sampling technique. A sampling frame of all first year students enrolled in the teaching learning process during the data collection period were obtained from Debre Markos Teachers Education College registrar office. Thus, the sample of the study was 260 students who were first year students in the study period at Debre Markos Teachers Education College.

\subsection{Data Analysis of the Study}

Based on the nature of the study, the researchers used document analysis method since the students ordered to write a paragraph about their biography. The written paragraph by the students were analyzed in line with Ferris (2005) category of errors analysis model which are Morphological Error (Verbs: Tense Form, Subject-verb agreement, Nouns: Noun endings (plural/possessive), Articles/determiners), Lexical Errors (Word choice, Word form, Informal usage, Pronoun error), Syntactic Errors (Sentence structure, Run-ons, Fragments), and Mechanical (Punctuation, Spelling, Capitalization) errors. Thus, data were grouped into four categories of errors with each respective sub-category and described with percentage.

\section{Data Analysis}

The study examined errors in the structure of an English paragraph in which learners made while they writing a paragraph. Based on the frame work of Ferris (2005) category of error analysis model, the collected data were classified into four major types of errors, and there were sub errors in each category. From participant students' paragraph, 1730 errors were identified and these errors categorized into four major errors. Based on the category, it was found that the total number of errors made by the students was stated on the following paragraph:

Table .1. Categories of Errors in Paragraphs

\begin{tabular}{|l|l|l|}
\hline Categories & Errors in the topic \\
\cline { 2 - 3 } & Error & Rate \\
\hline Morphological Errors & 604 & 34.9 \\
\hline Mechanical & 96 & 5.54 \\
\hline Syntactic & 542 & 31.3 \\
\hline Lexical Errors & 488 & 28.2 \\
\hline Total & 1730 & 100 \\
\hline
\end{tabular}

\subsection{Morphological Errors}

Morphological errors according to Ferris (2005) are errors which include verb errors, noun errors, and article or determiner errors. Based on the collected data, the morphological errors made by the students were presented quantitatively in the table below: 
Table.1. Morphological errors

\begin{tabular}{|c|c|c|c|c|}
\hline \multirow{4}{*}{ 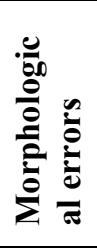 } & Types of errors & Errors in the topic & $\begin{array}{l}\text { Rate } \\
\text { morphological) }\end{array}$ & $\begin{array}{l}\text { Rate } \\
\text { (in all errors) }\end{array}$ \\
\hline & Verb error & 312 & $51.6 \%$ & $18.03 \%$ \\
\hline & Noun error & 174 & $28.8 \%$ & $10.05 \%$ \\
\hline & $\begin{array}{l}\text { Article or determiner } \\
\text { error }\end{array}$ & 118 & $19.5 \%$ & $6.8 \%$ \\
\hline \multicolumn{2}{|c|}{ Total morphological errors } & 604 & $100 \%$ & $34.9 \%$ \\
\hline
\end{tabular}

Frist year Debre Markos Teachers Education College students made different types of errors while they were writing paragraph. As the study indicated that they committed 1730 errors when they were writing paragraph about their biography. As shown in the above table, students frequently made morphological error since they committed $604(34.9 \%)$ morphological error from the total 1730 errors. These morphological errors were grouped into verb, noun, and article (determiner) errors. Under these categories, students made $312(51.6 \%)$ verb errors. This means that students could not maintain the subject verb agreement. As Ferris (2005) states, the verb errors include errors in verb tense, verb form (infinitive, gerund and other forms), and relevant subject-verb agreement. Most students could not consider the subject verb agreement in their writing as they used plural verb for singular subject. From the written paragraph, the following sentence is used as an example: 'My favorite subject are English'. Here, the subject is singular, but the verb which is bolded is plural. Besides, they made tense shift from past to present and present past. Of the demand of written communication, the intended meaning they want to communicate may be distorted.

Secondly, noun errors were found on the students' paragraph. Among 260 paragraphs, there were 174 (28.8\%) noun errors from $604(34.9 \%)$ morphological errors. These errors were $10.05 \%$ from the rate of total 1730 errors. From morphological errors, students made $118(19.5 \%)$ article or determiner errors. This was the least from the three morphological errors. This may be happened the students' frequency of usage of article or determiner was the least when we compare with other components of words.

\subsection{Lexical Errors}

According to Ferris (2005), lexical errors consist of all errors in word choice or word form, preposition errors, pronoun errors and spelling errors only in misspelling resulted of an actual English word. The following table indicates the degree of errors committed by first year Debre Markos Teachers Education College students in their written paragraph:

Table. 2. Lexical errors

\begin{tabular}{|l|l|l|l|l|}
\hline \multirow{3}{*}{} & Types of errors & Errors in the topic & Rate (in lexical errors) & $\begin{array}{l}\text { Rate } \\
\text { (in all errors) }\end{array}$ \\
\cline { 2 - 5 } & Error in word choice & 90 & 18.4 & 5.2 \\
\cline { 2 - 5 } & error in word form & 34 & 6.9 & 1.9 \\
\cline { 2 - 5 } & Preposition error & 58 & 11.8 & 3.4 \\
\cline { 2 - 5 } & Pronoun error & 18 & 3.6 & 1.06 \\
\cline { 2 - 5 } & Spelling error & 288 & 59 & 16.6 \\
\hline \multicolumn{2}{|l|}{ Total lexical errors } & 488 & 100 & 28.2 \\
\hline
\end{tabular}

\section{Errors in Word Choice}

This is inappropriate word selection.

Example: My brother is very long.

\subsubsection{Error in word choice}

Since students were not English native speakers, they made word choice errors. This means that they choose inappropriate words. As stated above table, 90(18.4\%) were word choice errors from the total 488(28.2) lexical errors. And word choice error was second highest error from lexical errors committed by first year students at Debre Markos Teachers Education College. This word choice error was 5.2\% from the total 1730 errors made by the students. From students' written paragraph, (My brother is very long) the word long is not the right word to construct the sample sentence. This type of error may be occurred due to students' mother tongue (Amharic language) influence although they have been taking English language since grade one and it is a medium of instruction both in high school and college of Ethiopian education system. Besides, word choice error, the students committed word form errors.

Among lexical errors, $34(6.9 \%)$ errors were word form errors. Students frequently made spelling errors which were $288(59 \%)$ and $16.6 \%$ from lexical and total errors respectively. Using wrong spellings will distort the intended meaning of the word on the written paragraph in English. For instance, 'I compiled secondary school in $2005^{\prime}$. Here, the writer of this sentence wants to say I completed secondary school, but what is written is different from what the writer intended to say. As result of spelling errors, students could not convey their 
intended message to readers since the spelling error brings meaning change that is totally different from the writers' intention. This spelling error may create confusion on readers mind and readers of written text with spelling errors will understand in different way. This brings communication barrier between the writer of the paragraph and the reader of it. On the other hand, pronoun errors and preposition errors were not frequently found on students' written paragraph.

\subsection{Syntactic Errors}

Syntactic errors are referred to as (1) phrase structure errors, (2) clause errors, (3) sentence errors, and (4) inter sentence errors. According to Ferris (2005) syntactic errors can be classified according to word order, omitted words or phrases, unnecessary words or phrases, run-ons, comma splices, fragments, and other unidiomatic sentence constructions.

Table. 3. Syntactic errors

\begin{tabular}{|l|l|l|l|l|}
\hline \multirow{3}{*}{} & Types of errors & Errors in the topic & Rate (in syntactic) & $\begin{array}{l}\text { Rate } \\
\text { (in all errors) }\end{array}$ \\
\cline { 2 - 5 } & Word Order & 108 & 19.9 & 6.2 \\
\cline { 2 - 5 } & Omitted Words or Phrases & 120 & 22.1 & 6.9 \\
\cline { 2 - 5 } & Unnecessary words or phrases & 102 & 18.8 & 5.8 \\
\cline { 2 - 5 } & Run-ons & 107 & 19.7 & 6.1 \\
\cline { 2 - 5 } & Fragments & 105 & 19.3 & 6.06 \\
\hline \multirow{2}{*}{ Total syntactic errors } & 542 & 100 & 31.06 \\
\hline
\end{tabular}

Utilizing the appropriate words in constructing a sentence makes the written paragraph effective, but the participants of the study used words in the wrong order. Study identified 108 (19.9\%) word order errors from the participants' paragraph. For instance: we live in family poor; from this sentence the word 'poor' is not used on its right place. The word 'poor' should modify the noun 'family', but it is placed after the modified word, family. This type of error commonly occurred on noun phrase.

In some parts of the paragraph, participants omitted word or phrases which are necessary for the effectiveness of the written paragraph. As it shown on the above table, 120 (22.1\%) of errors were omitted word or phrase errors from 542 syntactic errors. If the necessary words or phrases are omitted, it is so difficult to convey necessary information to the reader of the written paragraph. On the contrary, the participants used unnecessary words or phrases in their paragraph. This may alter the idea of the paragraph. In addition, participants committed basic sentence faults such as run-ons, comma splices and fragment faults.

\subsection{Mechanical Errors}

Ferris (2005) classifies mechanical errors into punctuation and capitalization errors. It mean that errors in which the students used wrong punctuation and wrong spelling capitalization. From the total errors students made, mechanical errors are the least as stated on the table.

Table 5 mechanical errors

\begin{tabular}{|c|c|c|c|c|}
\hline \multirow{3}{*}{ 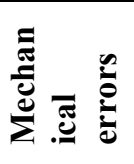 } & Types of errors & Errors in the topic & Rate (in mechanical) & $\begin{array}{l}\text { Rate } \\
\text { (in all errors) }\end{array}$ \\
\hline & punctuation & 44 & 45.8 & 2.5 \\
\hline & capitalization & 52 & 54.1 & 3 \\
\hline \multicolumn{2}{|c|}{ Total mechanical errors } & 96 & 100 & 5.5 \\
\hline
\end{tabular}

The students made 96 (5.5\%) mechanical errors from the total 1720 errors. This study identified two types of punctuation errors which were omission and addition. Some of the errors were omission of punctuation marks. On the other hand, the participants added punctuation marks. For example: She lives with step, mother. This sentence indicates that wrongly using comma. Comma is not necessarily for the example sentence. Therefore, omitting (missing) punctuation marks on necessary place and adding punctuation marks on the wrong place were made by students. Besides, participants made capitalization errors. In English language, first letter of specific nouns and the first letter of a sentence must be capitalized, but the participants did not make the first letter of proper nouns as it is stated the example below:

Now I live in debremarkos.

This shows capitalization error because the word debremarkos is proper noun, and it is the name of the place, so the first letter should be capitalized. The collected data indicated that the students, moreover, had inadequate knowledge of the capitalization rule in English in that the first letter of specific nouns and the first letter of a sentence must be capitalized. 


\section{Conclusions and Recommendations Conclusions}

The study has so far dealt with the common linguistic errors on students' paragraph writing in line with Ferris classification and identified four major errors. Thus, the study revealed the most frequent error types the students made were morphological errors, syntactic errors, lexical errors and mechanical errors. The most serious errors were morphological errors. Under these errors, verb errors, noun ending errors and article or determiner errors found. Syntactic errors placed as second level of students' errors. All errors in the sentence or clause boundaries are syntactic errors classified according to word order, omitted words or phrases, unnecessary words or phrases, run-ons, comma splices, fragments, and other unidiomatic sentence constructions which were identified from the students' written paragraphs. The finding indicated lexical errors as third level among the four major errors committed by the students. Lastly, mechanical errors were found on students' writings.

Based on the findings it is possible to conclude that many errors in the DMCTE first year students' writing were morphological errors. While the overall error rates help the researcher understand the students' overall performance, the specific errors the participants made frequently make help to clarify what the students' learning difficulties are. Secondly, many errors in the students' writing were syntactic errors. The students' writing in this study may have been related to the language structures of the students' first language: This finding is in line with some research that confirmed the interference from L1 in the process of EFL writing. Thirdly, regarding the errors of paragraph organization, the study shows that the students lack to use the appropriate transitional words to connect ideas.

\section{Recommendations}

This study identified errors in DMCTE students' written work, but did not stipulate reasons why these errors were made. My first recommendation is that this study be extended to investigating the origin of certain error patterns found in EFL written work of specific learners of the same mother tongue. An exploration of the composing process and determining the strategies learners use in EFL learning has not been considered in this study. In order to learn more about EFL writers' usage of language I would recommend that further research be conducted in this area. Moreover, in order to deal with the problem, some solutions are suggested as follows:

$>$ English language teachers should identify the most common type of errors committed by their students.

$>$ MOE and education bureau should give special attention for English language writing in the course outlines of English syllabuses for colleges.

$>$ Syllabus designers should include more free and controlled writing exercises that would help improve students writing abilities.

$>$ Teachers should then be more aware of these types of errors and provide the necessary follow up work to check the problem areas as discussed earlier.

$>$ However, EFL teachers and researchers cannot ignore error analysis as an important tool by which they can learn more about the psycholinguistic processes involved in the learning of a foreign language.

$>$ Besides, there should be more practical writing tasks for students in order to reduce errors in their writing.

$>$ error making is a necessary part of learning and language teachers should use the errors with a view of improving teaching

$>$ Teachers, educators and language study material developers should understand about the kind of errors that their target learners make.

Lastly, in order to explore the composing process of EFL writers meaningfully, we need to understand how students compose in both their native languages and in English. I, therefore, recommend that further studies on ethnographic research in EFL writing be conducted that examine the writing process, along with the acquisition of communicative competence.

In conclusion, making errors is inevitable in language learning process. Errors provide feedback about the effectiveness of the teaching techniques and show the teachers what part needs further attention. Studying the learner language in terms of errors is something that teachers have always done for practical reasons. It requires the teacher to have skills of diagnoses and treatment

\section{References}

Archibald, A. (2004). Writing in a second language. Retrieved March 20, 2006,

Baker, S. (1962). The Practical Stylist. New York: Thomas Y. Crowell Company.

Brown , H. Douglas ,(2007) (a) . Principles of Language Learning \&Teaching. $5^{\text {th }}$ edition , USA By Person Education ,Inc . .

Brown, C. (2000). The interrelation between speech perception and phonological acquisition from infant to adult. Great Britain: Blackwell Publishers Limited Crystal

Burt, M.K. and Kiparsky, C. (1972). The Gooficon: A Repair Manual for English. 
Burt, M.K. and Kiparsky, C. (1972). The Gooficon: A Repair Manual for English.

Caicedo, M. C. M. (2009). Native language interference in learning English as a

Carter 1993. The Stories of English. London: Penguin

Celce-Murcia, M. (2001). Teaching English as a second or foreign language

Chidambaram, K. (2005). A study on the learning process of English by higher

Cook, V.J. (1969). The analogy between first and second language learning. IRAL,

Corder, S. P. (1967). The significance of learners` errors. International Review of Applied Linguistics, 5, 161169.

Corder,S.P. (1971). Idiosyncratic Dialects and Error Analysis. IRAL,9,147-160.

Crystal, David (2005). The Stories of English. London: Penguin

Cunningsworth, A. (1987). Evaluation and selecting EFL teaching materials, p 87.

Cunningsworth, A. (1987). Evaluation and selecting EFL teaching materials, p 87. London: Heinemann Education Book.

Dulay, H.C. and Burt, M.K. (1974). "you cannot learn without Gooffing": An

Eckman , F. (1991). The structural conformity hypothesis and efficacy beliefs [Electronic version].Educational Psychology Review, 14, 173 - 203.

Ellis, R. (1996). Second language acquisition. (8th ed.). Oxford: Oxford University Press Ellis, R. (2003). Second language acquisition. (8th ed.). Oxford: Oxford University Press,

Ferris, D. (2002). Treatment of error in second language student writing. Ann Arbor: University of Michigan Press

Ferris, D.R. (2005).Treatment of error in second language writing. Ann Arbor: The University of Michigan Press.Foreign language: an analysis of written material produced by Spanish speaking students in Senior High school classes, from: http://www.lang.itsn.ac.uk/index.aspx. Celce-Murcia (2001).

Harmer, J. (2004). how to teach writing. Longman: Pearson Education Limited.

Hart, A.W. \& Reinking, J.A. (1990) Writing for College and Career. (4 ed.)

Hyland, K. (2003). Second Language writing. United Kingdom: Cambridge

James, C. (1998). Errors in language learning and use. Addison Wesley: Longman Inc. Keshavarz, M.H. (1994) Contrastive Analysis and Error Analysis. Tehran:

Khansir, A.A. (2008). Syntactic errors in English committed by Indian Undergraduate

Khansir, A.A. (2012). Error Analysis and Second Language Acquisition.

Klassen, R. (2001). Writing in early adolescents: A review of the role of self-

Lado, Robert .(1961). Language Testing : the Construction and Use of Foreign Language Tests . London: Longmans and LTD .Bristol. Linguistics, 10, 209-231.

McCarthy, M. 1991. Discourse analysis for language teachers. New York: Cambridg

McCarthy, M. 1991. Discourse analysis for language teachers.New York: Cambridge New York: St. Martin's Press Rajatanun (1988)

Norrish, J., 1983. Language Learners and Their Errors. 18. Khansir, A.A., 2012b. Study of the Syntactic Errors London: Macmillan Pres Perspectives on second language acquisition. London: Longman. Rahmana Pub.

Rajatanun, K. (1988) A Refresher Course in Writing. (2nd ed.) Bangkok: Thammasat University Press.

Richards , J . C . (1974). Error Analysis :Perspective on Second Language Acquisition. London :Longman Group Ltd.

Richards , J . C . (1974). Error Analysis :Perspective on Second Language 5th edition , USA By Person Education ,IncRowley: Newbury House.

Richards, J. C., and Schmidt, R. (2002). Dictionary of Language Teaching \& Applied Linguistics. Pearson Education Limited. London: Longman. secondary students with special reference to Dharmapuri district in Tamilnadu. Bloomfield, L. (1933). Language. New York: Holt. Khansir (2010).

Selinker, L. (1972). Interlanguage. International Review of Applied

Sivakumar, C. (1994). A linguistic study of the problems in learning Tamil by Tribal children.

Sridhar, S. (1981). Contrastive Analysis, Error Analysis and Interlangue: Three phases of one goal. In Fisiak, S. (1981) Contrastive Linguistics and the language teacher. Pergamon: Pergamon Press.

Swalles, J.M. (1990). Genre Analysis. Cambridge: Cambridge University Press.

Taylor, G. (1986). Errors and explanations. Applied Linguistics. 7: 144-66. the Nilgiris. Mysore: Central Institute of Indian Languages. Silver Jubilee Publication. Theory and Practice in Language Studies, 2, $1027-$ 1032. University Press.

Xie, F., and Jiang, X. (2007, September). Error analysis and the EFL classroom teaching, p 13. College of Foreign Languages, Liaoning Normal University, Dalian Liaoning(3rd ed.). Boston: Heinle \& Heinle. 